\title{
IMMUNOHISTOCHEMICAL LOCALIZATION OF TYPES I, III AND IV (BASEMENT MEMBRANE) COLLAGENS IN THE LYMPH NODE: CO-DISTRIBUTION OF TYPES I AND III COLLAGENS IN THE RETICULAR FIBERS
}

\author{
HIROSHI KONOMI, JUNJIRO SANO and YUTAKA NAGAI
}

Department of Tissue Physiology, Medical Research Institute, Tokyo Medical and Dental University, Kandasurugadai, Chiyodaku, Tokyo 101, Japan

\begin{abstract}
The tissue distribution of types I, III and IV (basement membrane) collagens in normal bovine lymph nodes was examined by indirect immunofluorescence microscopy, using rabbit antibodies type-specific to individual types of bovine collagens, and compared with the distribution of argyrophilic components in the same tissue sections stained by the Pap method (double staining) after immunohistochemical analysis.

Types I and III collagens were distributed on the reticular fibers in lymph sinuses, cortex and medulla as well as on the interstitium of the capsule and trabeculae, but were not detected in lymph follicles, though rather dense distribution of the fibers consisting of both types of collagens was observed around the follicles.

Type IV collagen is located in the walls of blood vessels and lymph sinuses in a linear fashion, while, in the lymph cortex, the collagen is distributed discontinuously like a honeycomb which can be easily distinguished from the reticular fibers. The presence of type IV collagen in the lymph follicles was seen only when small capillaries were detected.
\end{abstract}

Type II collagen was not observed in any region of the lymph nodes examined.

KEY WORDS collagen / antibody / immunofluorescent microscopy / lymph node / reticular fibers

In recent years, the molecular heterogeneity of collagen has been well characterized and at least five genetically distinct collagens (types $\mathrm{I}-\mathrm{V}$ ) have been found in mammalian tissues (3). Biochemical and immunohistological studies on these collagens have shown that their distribution in tissues and organs is type-specific, thus providing architectural organizations for individual tissues to function properly (3).

Both type I and type III collagens are known to be widely distributed in collagen fibers in vivo, regardless of the sizes of fibers $(10,11)$, except for certain tissues such as bone (3), tendon (3, 9) and sclera (unpublished data) where type I collagen is the primary component, and the intima and media of aorta $(3,9)$, where type III collagen is concentrated.

As regards reticular fibers, which had been classified as a family of thin fibers distinct from collagen fibrils and fibers, based on their argyrophilic properties, Gay et al. have reported from immunohistochemical studies that type III collagen is present in the liver parenchyma as a loose network corresponding to reticular fibers, while type I collagen is only in small fiber bundles which are irregularly distributed in the parenchyma $(2,5,8)$. However, our recent immunohistochemical studies on collagen types in 
the liver have revealed that both type I and type III collagens are present in the perisinusoidal spaces of human and bovine liver parenchyma as thin fibers like reticular fibers. No significant differences in distribution of the two collagen types were observed under the experimental conditions employed (7). These results prompted us to further examine reticular fibers for collagen types.

This paper describes an immunohistochemical analysis of type-specific distribution of collagens in the lymph node, which is one of the typical reticuloendothelial systems, and compares the collagen types with argyrophilic components visualized by silver staining of the identical tissue sections examined for collagen types.

\section{MATERIALS AND METHODS}

\section{Type-Specific Anti-Collagen Antibodies}

Type-specific rabbit antibodies against types I and III collagens (from fetal calf skin), type II collagen (from bovine articular cartilage) and type IV collagen (from bovine glomerular basement membranes) were those used in a recent study (6). The antibodies showed no crossreaction with other types of collagens in the passive hemagglutination assay (6).

\section{Indirect Immunofluorescent Staining}

Fresh normal bovine submaxillary lymph nodes were snap frozen with $n$-hexane cooled with dry ice-acetone. Six-eight $\mu \mathrm{m}$ sections of the sample tissues sliced in a cryostat were mounted on glass slides, air-dried and pretreated with acetone for $10 \mathrm{~min}$. The sections were incubated with antibodies to bovine type I, II, III or IV collagen, diluted $1: 2,1: 16,1: 16,1: 16$, respectively, with $0.15 \mathrm{M} \mathrm{NaCl}$ in $0.05 \mathrm{M}$ Tris-HCl buffer, $\mathrm{pH} 7.5$, in a moist chamber for $60 \mathrm{~min}$ at room temperature, and then rinsed in several changes of phosphate-buffered saline, pH 7.2. The sections were subsequently stained with fluoresceinisothiocyanate-labeled anti-rabbit IgG goat IgG (MBL Co., Nagoya), diluted $1: 16$ with saline for $60 \mathrm{~min}$, rinsed with phosphate-buffered saline and mounted in $50 \%$ glycerol in the same buffer. The stained sections were observed in a Nikon FL fluorescence microscope, as reported previously $(6,7)$. As a control, another set of sections was incubated with non-immunized rabbit serum, diluted 1:16 with saline, in place of anti-collagen antibodies.

\section{Histochemical Staining}

The sections of lymph nodes, which had been stained with anti-collagen antibodies and examined by fluorescence microscopy, were dipped in phosphate-buffered saline overnight to strip the mounted cover glasses, then subjected to silver staining by the Pap method or hematoxylin-eosin staining and examined by light microscopy.

\section{RESULTS}

Reactions with Antibodies to Type I, Type II, or Type III Collagen

Staining for type I and type III collagens in the lymph node showed a clear delineation of the interstitium of the capsule, trabeculae, and blood vessels as thick fibers and formed a fine meshwork in the lymph sinuses, cortex and medulla like reticular fibers (Figs. 1 and 2). Both types of collagens were not detected in the center of the lymph follicles, except for a certain region where amorphous components were occasionally detected by the stainings. Dense distribution of types I and III collagens was observed around the lymph follicles (Figs. 1-3).

Double staining of identical tissue sections with anti-collagen antibodies and the Pap method revealed that both type I and type III collagens were on the reticular fibers, regardless of the sizes of the fibers (Figs. 4 and 5). The presence of type II collagen was not detected in any region of the lymph nodes examined, in spite of immunohistochemical analysis with anti-type II collagen antibodies (data not shown).

\section{Reactions with Anti-Type IV (Basement Membrane) Collagen Antibody}

Staining for type IV collagen showed a clear delineation of the walls of blood vessels and lymph sinuses (Figs. 6 and 7) as well as of the peripheral regions of the reticular fibers in lymph sinuses (Fig. 7). However, in the cortex, a discontinuous meshwork like a honeycomb, which could be easily distinguished from reticular fibers, was observed (Figs. 6 and 8). Neither capsule nor trabeculae reacted with the antibodies. The presence of type IV collagen in lymph follicles was observed only when small capillaries were detected (Fig. 6).

\section{DISCUSSION}

The lymph node consists of capsule, trabeculae, 


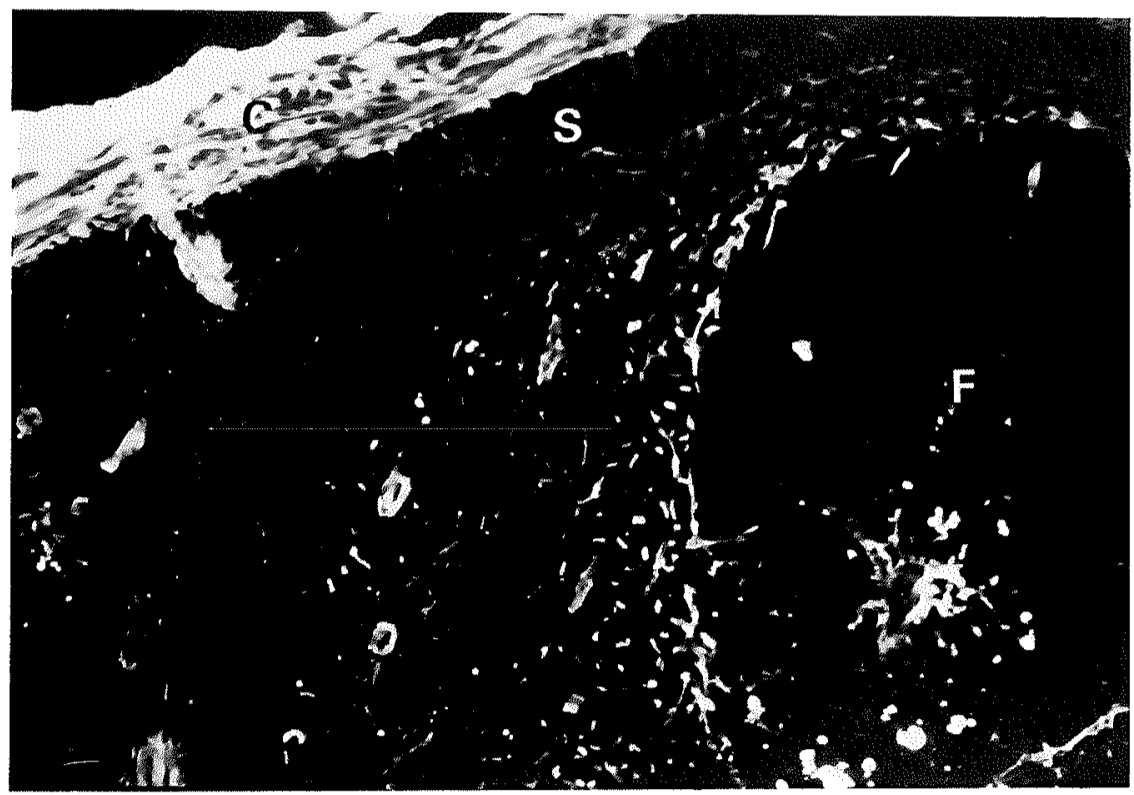

Fig. 1 A section of the cortex of a lymph node stained with an antibody to type I collagen. $\mathrm{S}$, lymph sinus. The interstitium of the capsule $(\mathrm{C})$ is stained as thick fiber bundles and the cortex except for lymph follicles $(F)$ is stained like reticular fibers. $\times 185$

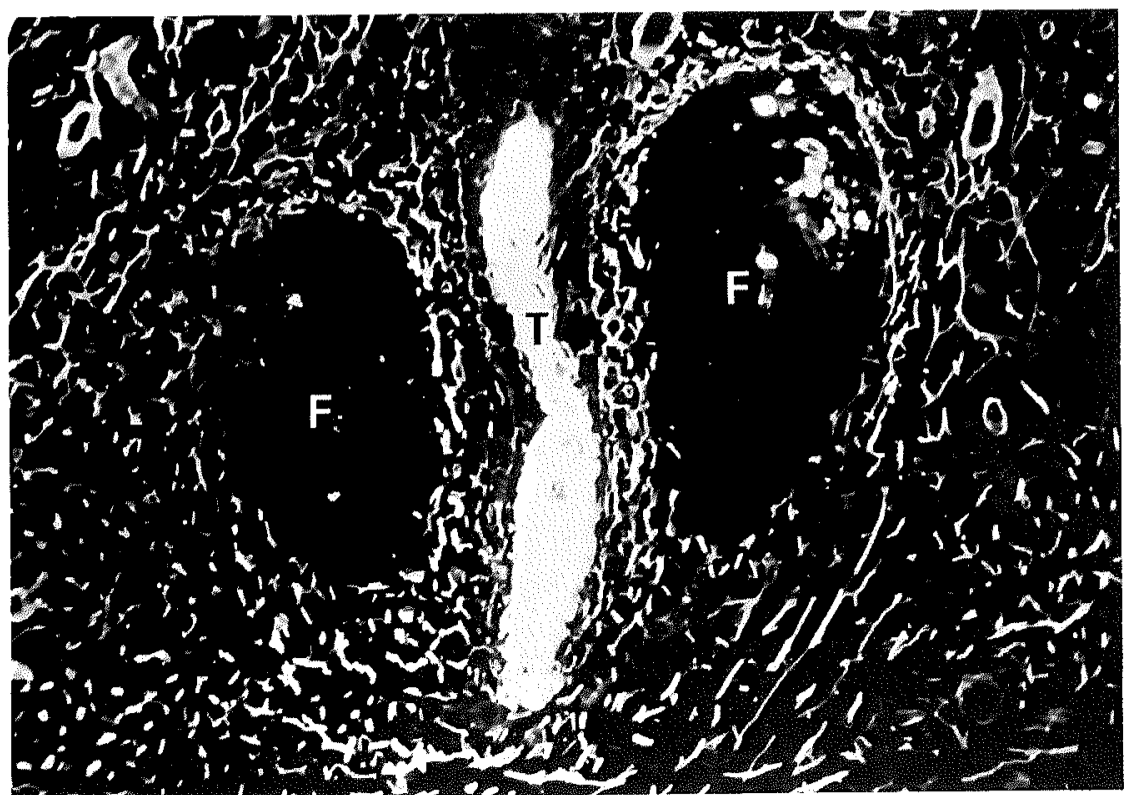

Fig. 2 A section of a deep cortex region of lymph node stained with an antibody to type III collagen. The interstitium of the trabecula $(T)$ is stained as thick fiber bundles and the cortex except for lymph follicles $(F)$ is stained like reticular fibers. $\quad \times 170$ 

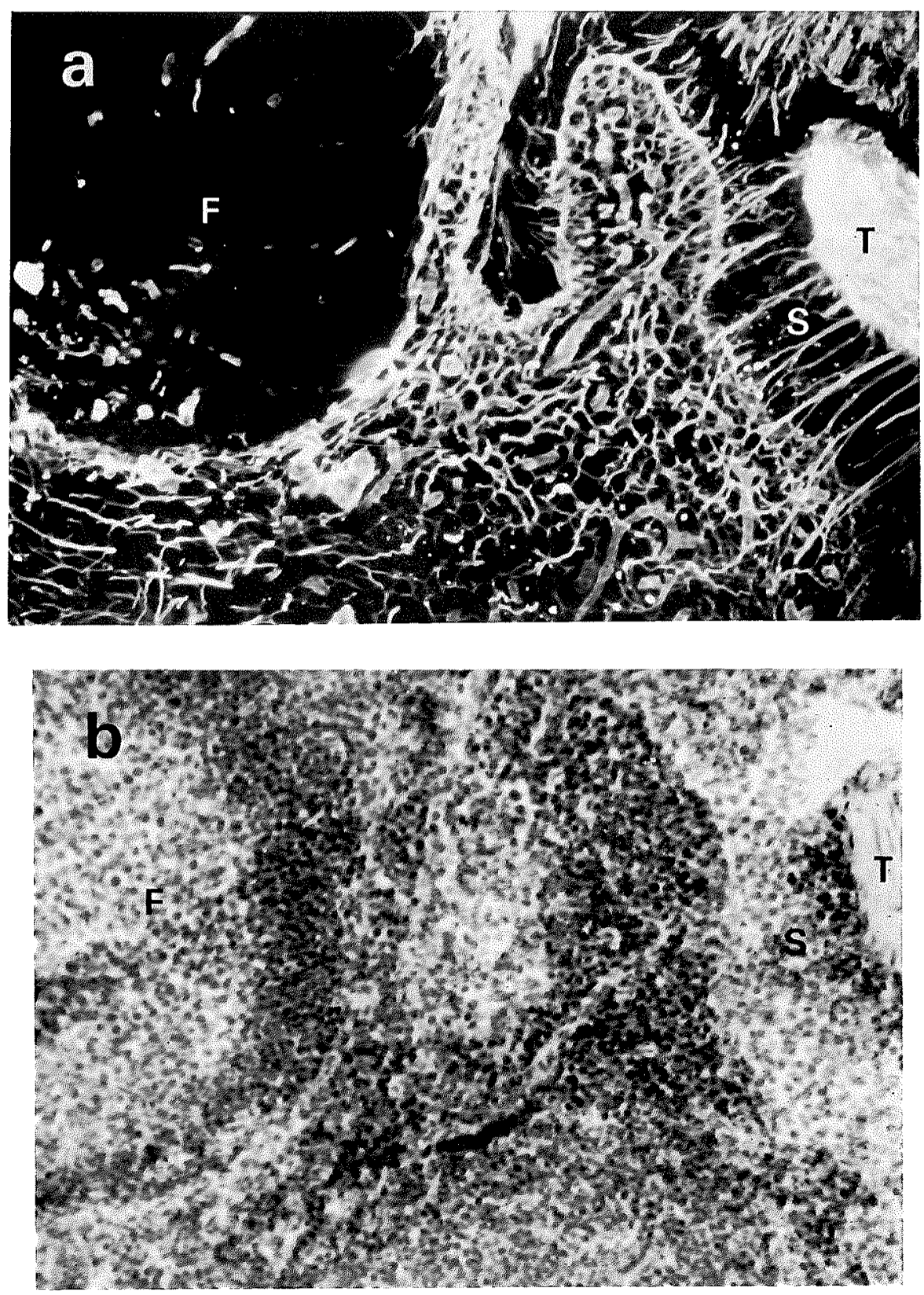

Fig. 3 A section of lymph node cortex stained with an antibody to type III collagen (a) and hematoxylin-eosin staining of the same section (double staining) (b). T, trabecula; $S$, lymph sinus. Collagen fibers are hardly detected in the lymph follicle $(F)$, though rather dense distribution of the fibers is observed around the follicle. $a, \times 185$. b, $\times 220$ 

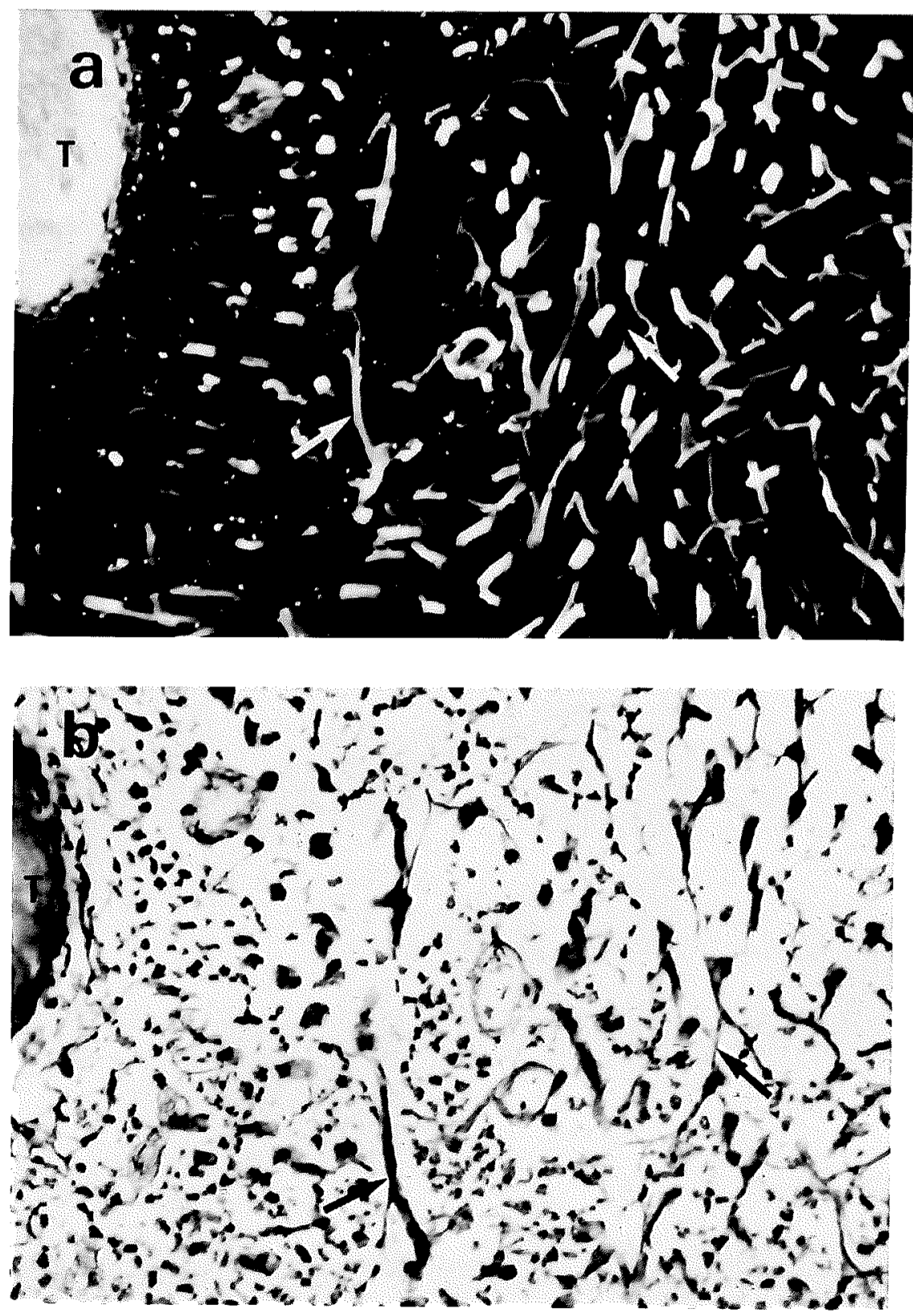

Fig. 4 A section of lymph node cortex stained with an antibody to type I collagen (a), and silver staining of the same section (double staining) (b). T, trabecula. Reticular fibers are sharply stained with the antibody, regardless of size $(\uparrow)$, a, $\times 350$. $b, \times 410$ 

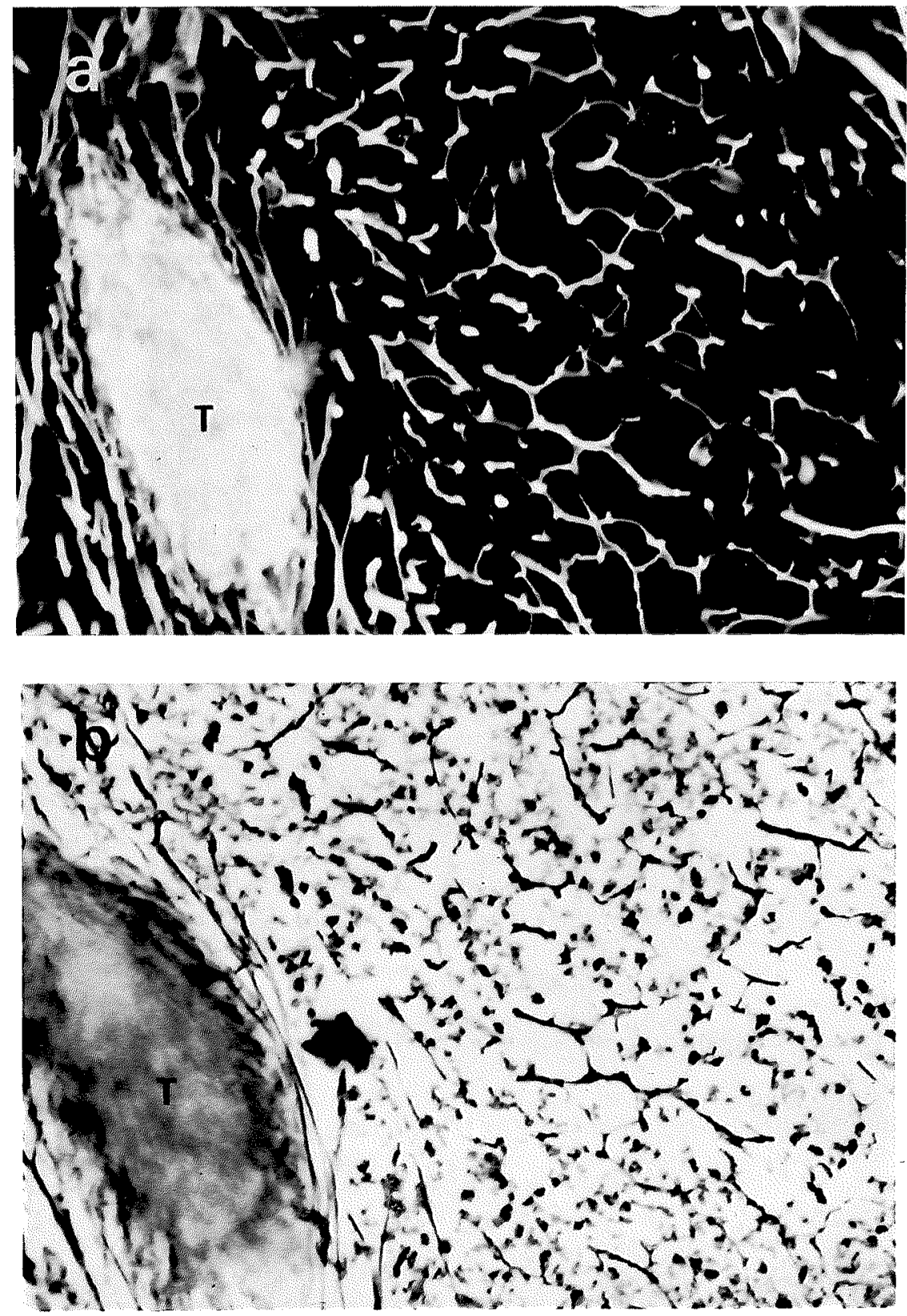

Fig. 5 A section of lymph node cortex stained with an antibody to type III collagen (a), and silver staining of the same section (double staining) (b). T, trabecula. Reticular fibers are sharply stained with the antibody in the same way as with anti-type I collagen antibody. a, $\times 360$, b, $\times 420$ 


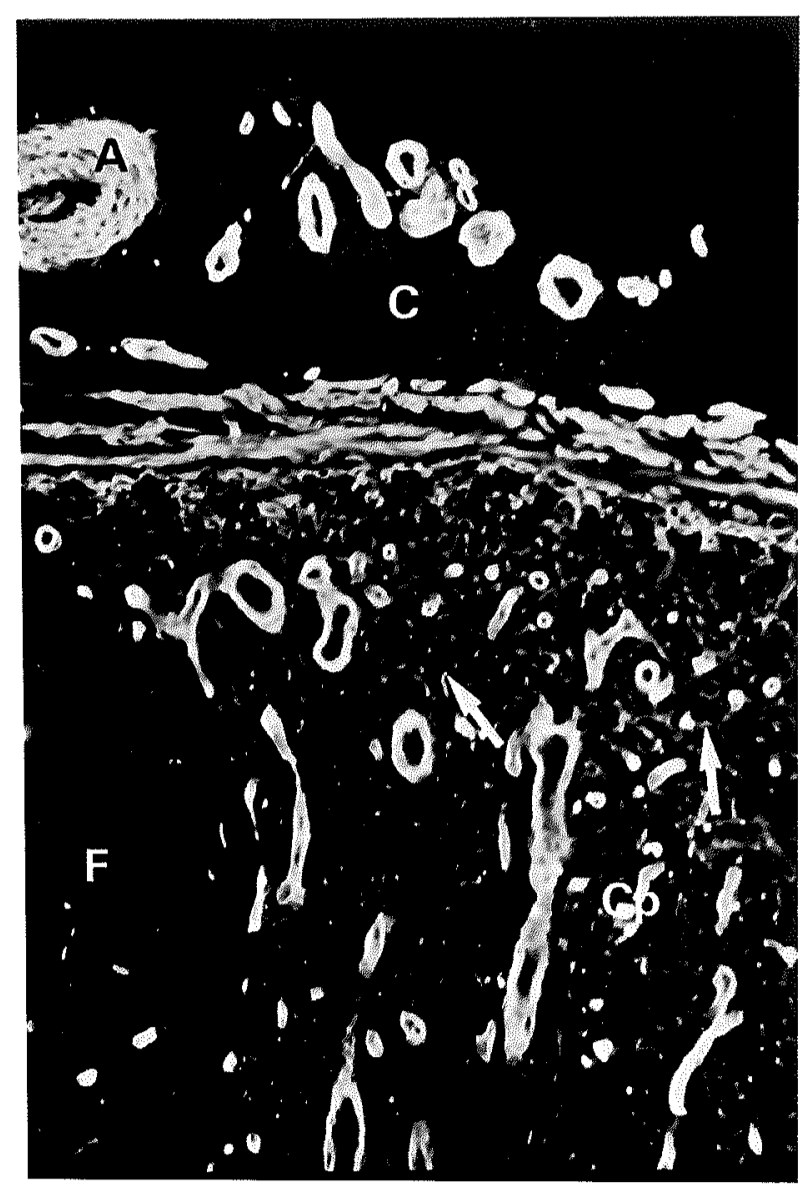

Fig. 6 A section of lymph node cortex stained with an antibody to type IV collagen. The interstitium of the capsule $(C)$ and lymph follicle (F) are not stained, except for arteries (A) and capillaries $(\mathrm{Cp})$ which are stained in a linear fashion. The cortex is stained discontinuously like a honeycomb to make a number of compartments $(\uparrow) . \quad \times 180$

reticular fibers, lymphocytes, other free cells, blood and lymphatic vessels and nerves. The capsule and trabeculae are composed of dense connective tissue making a framework for the node, and the reticular fibers form a fine meshwork in the space enclosed by the capsule and trabeculae $(1,12,13)$. Our present results have revealed that the fibrous components in the lymph node including reticular fibers are all composed of hybrid structures of type I and type III collagens. No specific fibers consisting of a particular type of collagen were detected in the lymph node, in spite of the use of double staining with type-specific anti-collagen antibodies and the Pap method. Our previous studies on collagen types in bovine and human liver paren- chyma have shown that both type I and type III collagens are present as thin fibers in the perisinusoidal space (7) and immunoelectron microscopic analysis has revealed that both types of collagens were present in collagen fibrils in Disse's space of bovine liver parenchyma (9). These results are consistent with the observations in this study.

In lymph sinuses, type IV (basement membrane) collagen was detected lying like endothelial basement membranes on both sides of the reticular fibers located by the Pap method. This is consistent with an earlier observation by Ishii (4) who employed a modification of the Bielschowsky-Maresch's method for detection of the basement membranes in lymph sinuses. 

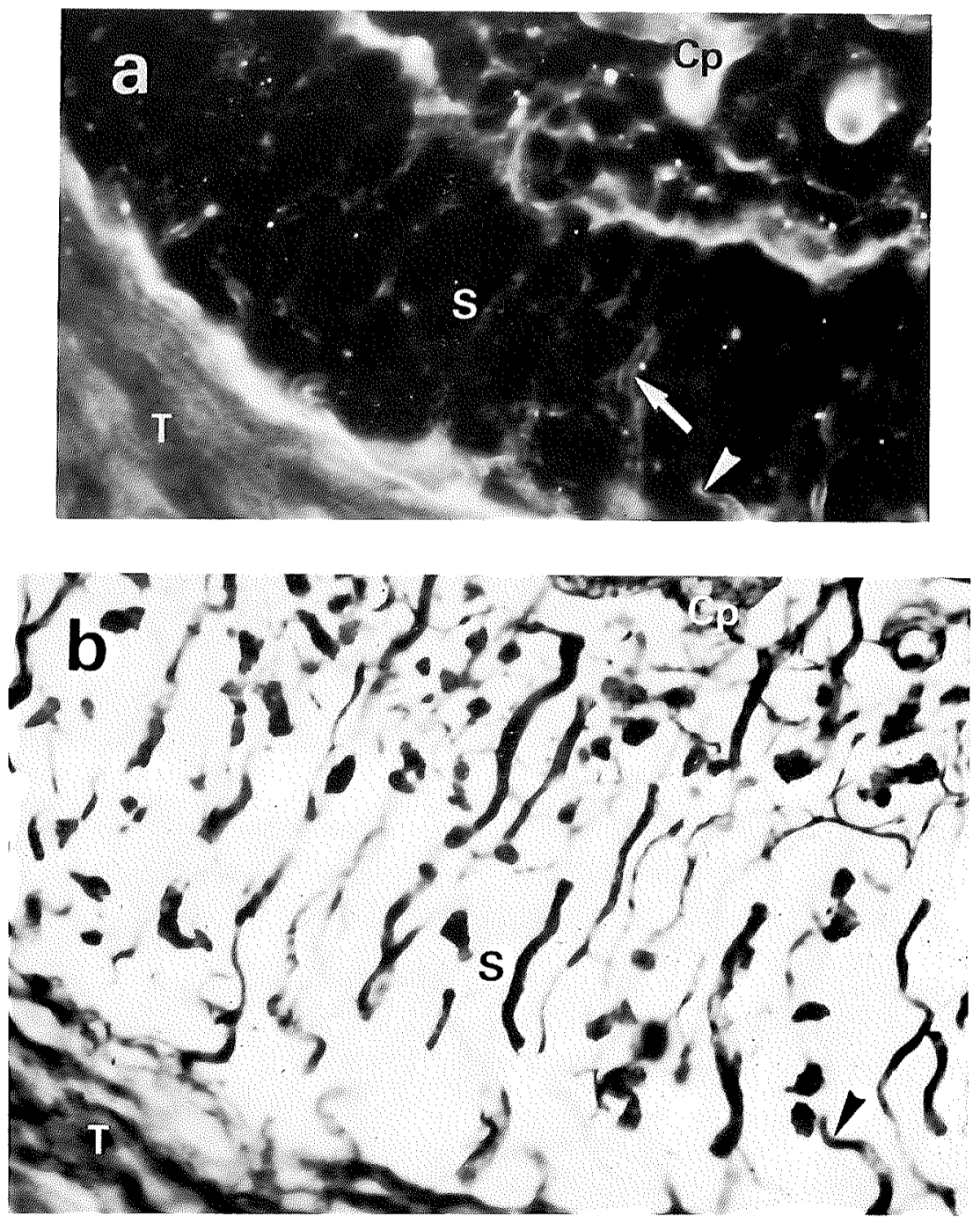

Fig. 7 A section of a lymph sinus stained with an antibody to type IV collagen (a), and silver staining of the same section (double staining) (b). S, lymph sinus; $\mathrm{T}$, trabecula; $\mathrm{Cp}$, capillaries. Arrowheads locate the identical point on the tissue sections a and $b$. Inner and outer walls of lymph sinus are stained in a linear fashion. The antibody has also reacted with peripheral regions on both sides of reticular fibers in the sinus $(\uparrow)$. a, $\times 715$. b, $\times 930$

However, distribution of type IV collagen in the cortex was entirely different from that of the reticular fibers visualized by the Pap method. Type IV collagen was distributed like a honeycomb in the tissue. This would provide a number of compartments there to accommodate a set of cells with a proper function or to facilitate cell transportations during maturation. In this connection, it should be noted that neither interstitial collagens nor basement membrane collagen were detected in the center of lymph follicles.
This work was supported in part by a grant for the Special Project Research (Connective Tissue Diseases) from the Ministry of Education, Science and Culture, Japan.

Received for publication 26 Jume 1981 

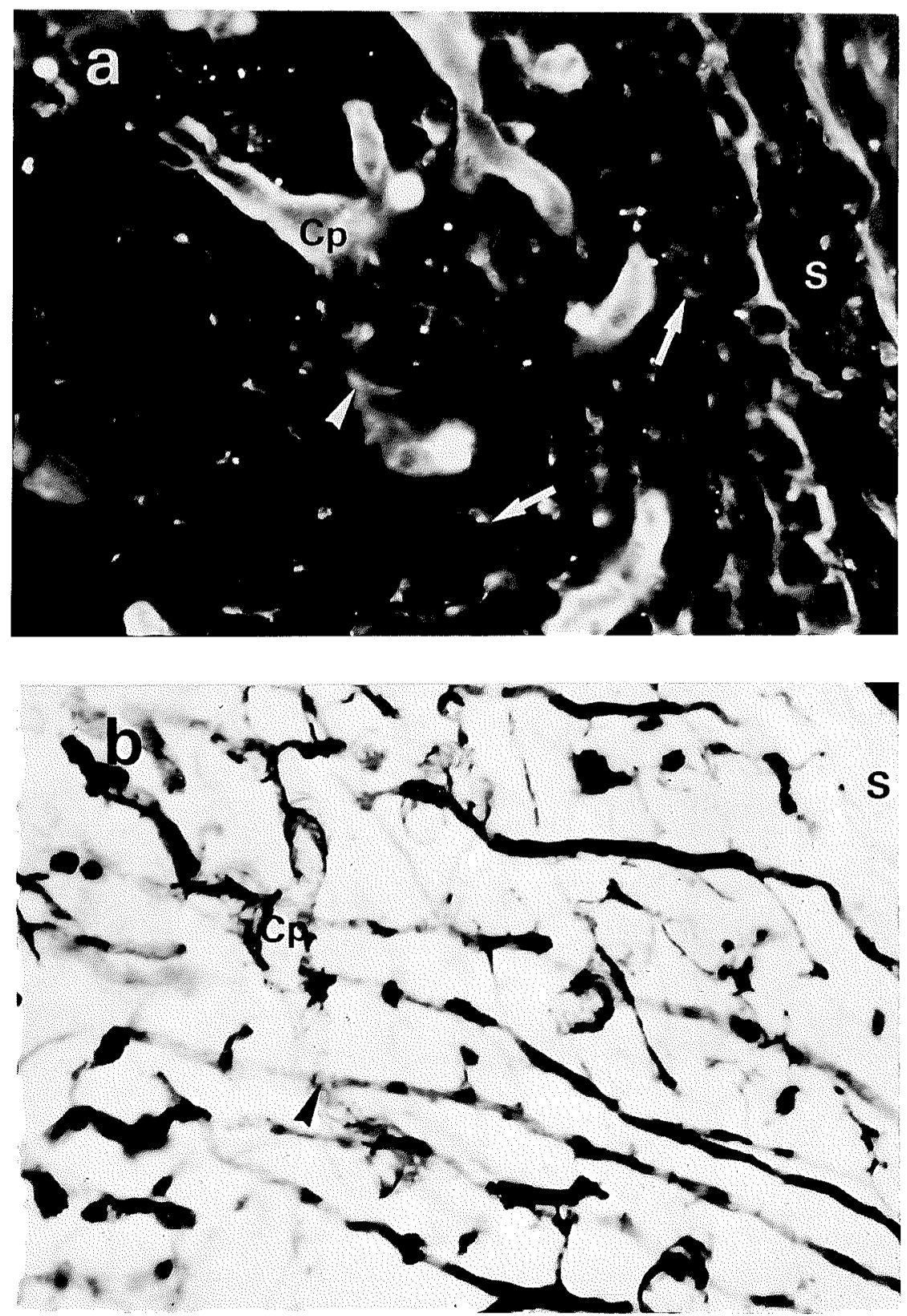

Fig. 8 A section of lymph node cortex stained with an antibody to type IV collagen (a), and silver staining of the same section (double staining) (b). S, lymph sinus; Cp, capillaries. Arrowheads locate the identical point on the tissue sections $a$ and $b$. The cortex is stained discontinuously like a honeycomb and can be easily distinguished from the reticular fibers $(\uparrow), \quad a, \times 700 . \quad b, \times 840$ 


\section{REFERENCES}

1. Bloom W. and Fawcett D. W. (1975) A Textbook of Histology 10th Ed., W. B. Saunders, Philadelphia/London/Toronto, pp. 165-167

2. Gay S., Fietzek P. P., Remberger K., Eder M. and KÜHN K. (1975) Liver cirrhosis: Immunofluorescence and biochemical studies demonstrate two types of collagen. Klin. Wochenschr. 53, 205-208

3. GAY S. and Miller E. J. (1978) Collagen in the Physiology and Pathology of Connective Tissue. Gustav Fischer Verlag, Stuttgart/New York

4. IsHII T. (1966) Über den lichtmikroskopischen Feinbau der Retikulumfasern des Lymphknotens (ein Beitrag zur Frage von Natur und Aufbau der Retikulumfasern). Proc. Jap. Soc. Reticuloendothelial System 6, 24-37

5. Kent G., Gay S., Inouye T., Bahu R., Minick O. T. and POPPER H. (1976) Vitamin A-containing lipocytes and formation of type III collagen in liver injury. Proc. Natl. Acad. Sci. USA 73, 3719-3722

6. Konomi H., Hori H., Sano J., Sunada H., Hata R., Fujiwara S. and Nagai Y. (1981) Immunohistochemical localization of type I, II, III and IV collagens in the lung. Acta Pathol. Japon. 31, 601-610

7. Konomi H., SANo J, and NagaI Y. (1981) Immunohistochemical localization of type I, III and
IV (basement membrane) collagens in the liver. Acta Pathol. Japon. 31, 973-978

8. Nowack H., Gay S., Wick G., Becker U. and TIMPL R. (1976) Preparation and use in immunohistology of antibodies specific for type I and type III collagen and procollagen. J. Immunol. Methods 12, 117-124

9. Sano J., Sato S., Ishizaki M., Yajima G., Konomi H., Fujiwara S. and Nagai Y. (1981) Types I, III and IV (basement membrane) collagens in the bovine liver parenchyma: Electron microscopic localization by the peroxidaselabeled antibody method. Biomedical Res. 2 (5), 546-551

10. TAJima S. and NagaI Y. (1980) Isolation and partial characterization of collagen fibrils, fibers and fiber bundles from insoluble calf dermis. Connect. Tissue Res. 7, 157-163

11. Tajima S. and Nagal Y. (1980) Distribution of macromolecular components in calf dermal connective tissue. Connect. Tissue Res. 7, 65-71

12. WeIss L. (1977) Lymphatic vessels and lymph nodes. In Histology (ed. WeISS L. and GreEP R. O.) 4th Ed., McGraw-Hill, New York/St. Louis/San Francisco, pp. 523-544

13. Wheater P. R., Burkitt H. G. and Daniels V. G. (1979) Lymph nodes. In Functional Histology: A Text and Colour Atlas, Churchill Livingstone, Edinburgh/London/New York, pp. 150157 